DOI: http://doi.org/10.21698/simi.2018.ab39

\title{
RAPID VOLTAMMETRIC ANALYSIS OF MONOLINURON AND LINURON HERBICIDES
}

\author{
Mihaela Buleandră, Dana-Elena Popa, Iulia Gabriela David, Victor David, Anton Alexandru \\ Ciucu \\ University of Bucharest, Faculty of Chemistry, Department of Analytical Chemistry, Panduri \\ 90-92 Av., 050663, Bucharest, dana_lena1978@yahoo.com, Romania
}

Keywords: electrochemically pre-treated pencil graphite electrode, linuron, monolinuron

\section{Introduction}

Monolinuron, MLN (3-(4-chlorophenyl)-1-methoxy-1-methylurea) and linuron, LIN (3-(3,4-dichlorophenyl)-1-methoxy-1-methylurea) are phenyl urea herbicides applied in agriculture to control the broadleaf and grassy weeds. Some of these compounds are considered endocrine disruptors due to the fact that they produce reproductive toxicity in animals by acting as androgen receptor antagonist. So far, there are various determination methods for MLN and LIN in the literature, especially chromatographic ones, but there is no electrochemical method for simultaneous quantification of the two herbicides. Thus, the objectives of the present work were the study of the individual and simultaneous electrochemical behavior of these herbicides by cyclic voltammetry (CV) and the quantitative determination by differential pulse voltammetry (DPV) using a disposable pencil graphite electrode (PGE). The PGE was chosen due to its good conducting properties and its economic advantages, mentioning the fact that this type of carbonaceous material has not been used for the determination of these analytes.

\section{Materials and methods}

A PGSTAT 128N Autolab electrochemical system and Nova 1.8 software were used for the voltammetric experiments. Electrochemically pre-treated Rotring HB pencilleads as working electrode, an $\mathrm{Ag} / \mathrm{AgCl}$ electrode as reference electrode and a platinum wire as auxiliary electrode were the three electrodes that constituted the electrochemical cell. PGE was activated by an electrochemical pre-treatment (PGE*) using the $\mathrm{CV}$ from $-0.2 \mathrm{~V}$ to $+3.0 \mathrm{~V}$ at a scan rate of $500 \mathrm{mV} \cdot \mathrm{s}^{-1}$ in Britton-Robinson buffer (BRB) $\mathrm{pH}$ 6.80. A new graphite pencil lead was used for each voltammetric measurement.

$1 \cdot 10^{-2} \mathrm{~mol} \cdot \mathrm{L}^{-1} \mathrm{MLN}$ and LIN stock solutions were prepared by dissolving the required amounts of herbicides in methanol. For all analyses, the required volume of the stock solution was introduced into a $10 \mathrm{~mL}$ volumetric flask and diluted to the mark with BRB solution, $\mathrm{pH}$ 3.29. CV between +0.6 and $+1.6 \mathrm{~V}$ was used for the electrochemical characterization of the compounds. DPV was used for the quantitative determination of both herbicides. The DP voltammograms were recorded by scanning the potential toward positive direction from $+0.5 \mathrm{~V}$ to $+1.5 \mathrm{~V}$. 


\section{INTERNATIONAL SYMPOSIUM "THE ENVIRONMENT AND THE INDUSTRY", SIMI 2018, BOOK OF ABSTRACTS}

\section{Results and conclusions}

Cyclic voltammetry studies of herbicides in single and mixed solutions $\left(1 \cdot 10^{-4} \mathrm{~mol} \cdot \mathrm{L}^{-}\right.$ ${ }^{1}$ each in BRB pH 3.29) showed that well-defined oxidation peaks appeared on PGE* at $+1.17 \mathrm{~V}$ for MLN and at about $+1.2 \div+1.3 \mathrm{~V}$ for LIN (Figure 1). On the contrary, $\mathrm{CV}$ responses of the herbicides mixture on PGE overlap to form a wide oxidation peak at $1.24 \mathrm{~V}$ (inset of Figure 1). For MLN and LIN individual measurements on PGE* the peak currents were almost ten times higher than those generated at untreated PGE.

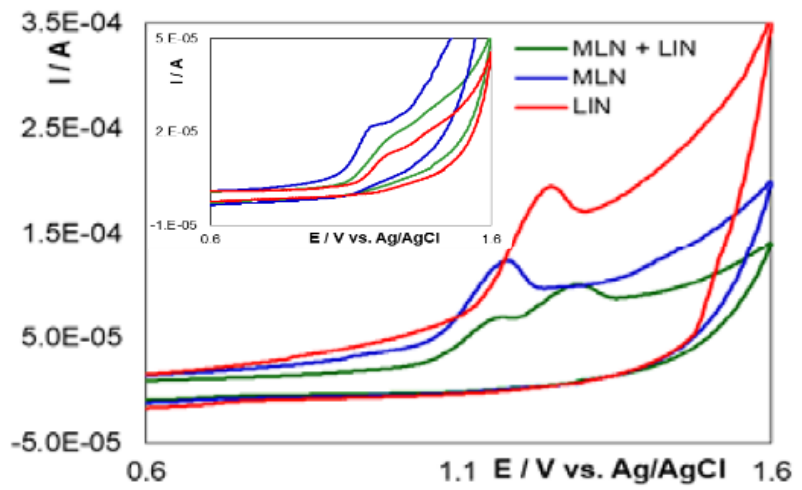

Figure 1. Cyclic voltammograms of $1 \cdot 10^{-4} \mathrm{~mol} \cdot \mathrm{L}^{-1} \mathrm{MLN}$, LIN and mixture of them in $\mathrm{BRB}$ pH 3.29 at $\mathrm{PGE}^{*}$, scan rate $100 \mathrm{mV} \cdot \mathrm{s}^{-1}$ (inset, CVs on PGE).

$\mathrm{CV}$ behavior of a mixed solution containing MLN and LIN in BRB of different $\mathrm{pH}$ values at PGE* $^{*}$ showed that the best defined signals and peaks separation (of about $100 \mathrm{mV}$ ) were obtained at $\mathrm{pH} 3.29$. At $\mathrm{pH}$ above 6.80 only one wider peak appeared, emphasizing that the simultaneously determination cannot be done in neutral or alkaline media.

The effect of $\mathrm{pH}$ on voltammetric response of each compound in BRB solutions at PGE* showed that in the $1.81 \div 11.58 \mathrm{pH}$ range the analytes behave differently resulting that at $\mathrm{pH}$ below 7.96 the protons number involved in the electrochemical process is twice than the electrons number, while at $\mathrm{pH}$ higher than 7.96 the protons number is equal to the electrons number. The mixture analysis at $\mathrm{pH}<6.80$ proved a similar behavior with the individual ones in acidic medium.

The influence of the scan rate on the MLN and LIN peaks proved that the electrooxidation of the compounds is a diffusion-controlled process, and the calculated electrons number was 2 for each analyte.

The quantitative simultaneously determination of the herbicides by DPV showed two linear ranges: $7.5 \cdot 10^{-7}-7.5 \cdot 10^{-6} \mathrm{~mol} \cdot \mathrm{L}^{-1}$ and $7.5 \cdot 10^{-6}-1 \cdot 10^{-4} \mathrm{~mol} \cdot \mathrm{L}^{-1}$ for $\mathrm{MLN}$; $7.5 \cdot 10^{-7}-1 \cdot 10^{-5} \mathrm{~mol} \cdot \mathrm{L}^{-1}$ and $1 \cdot 10^{-5}-1 \cdot 10^{-4} \mathrm{~mol} \cdot \mathrm{L}^{-1}$ for LIN. The calculated detection limits for MLN and LIN were $3.7 \cdot 10^{-7}$ and $5.8 \cdot 10^{-7} \mathrm{~mol} \cdot \mathrm{L}^{-1}$, respectively.

The DPV method was applied to synthetic samples using standard addition method. For the spiked samples the percentage recoveries were calculated, all values lying between the accepted limits for the considered concentration levels.

In conclusion, the electrochemical behavior of MLN and LIN on PGE* has been studied, highlighting that the electrochemical pre-treatment of PGE enables the simultaneous determination of the herbicides. The method is simple, rapid and affordable, yielding to reliable analytical results.

\section{Acknowledgements}

This work was supported by the University of Bucharest, research project UB 2045/2018. 